\title{
Performance of a Y-Ba-Cu-O Superconducting Filter/GaAs Low Noise Amplifier Hybrid Circuit
}

K.B. Bhasin and S.S. Toncich

National Aeronautics and Space Administration

Lewis Research Center

Cleveland, Ohio

C.M. Chorey

Sverdrup Technology, Inc.

Lewis Research Center Group

Brook Park, Ohio

and

R.R. Bonetti and A.E. Williams

COMSAT Laboratories

Clarksburg, Maryland

Prepared for the

1992 IEEE MTT-S International Microwave Symposium

Albuquerque, New Mexico, June 2-4, 1992

\section{N/Sก}

$$
\begin{aligned}
& \text { (NASA-TM-105546) PERFORMANCE OF A } Y-3 \mathrm{a}-\mathrm{CU}-\mathrm{O} \\
& \text { SUPERCUNUUCTING FILTEP/GAAS LOW NOISE } \\
& \text { AMPLIFIFR HYPIO CIRCUIT (NASA) } 5 \mathrm{P}
\end{aligned}
$$


PERFORMANCE OF A Y-Ba-Cu-O SUPERCONDUCTING FILTER/GaAs

\title{
LOW NOISE AMPLIFIER HYBRID CIRCUIT
}

\author{
K.B. Bhasin and S.S. Toncich \\ National Aeronautics and Space Administration \\ Lewis Research Center \\ Cleveland, Ohio 44135 \\ C.M. Chorey \\ Sverdrup Technology, Inc. \\ Lewis Research Center Group \\ Brook Park, Ohio 44142 \\ R.R. Boneti and A.E. Williams \\ COMSAT Laboratories \\ Clarksburg, Maryland 20871
}

\begin{abstract}
A superconducting $7.3 \mathrm{GHz}$ two-pole microstrip bandpass filter and a GaAs low noise amplifier (LNA) were combined into a hybrid circuit and characterized at liquid nitrogen temperatures. This superconducting/semiconducting circuit's performance was compared to a gold filter/GaAs LNA hybrid circuit. The superconducting filter/GaAs LNA hybrid circuit showed higher gain and lower noise figure than its gold counterpart.
\end{abstract}

\section{$\underline{\text { Introduction }}$}

Before the discovery of high-Tc superconductivity, the integration of low-Tc superconductors with semiconducting devices was not feasible since many semiconducting devices freeze-out below $10 \mathrm{~K}$. The recent demonstration of high-Tc superconducting passive microwave components operating at liquid nitrogen temperatures ${ }^{1,2}$ has enhanced the feasibility of integrating these superconducting components with semiconducting devices to achieve high performance microwave systems. GaAs and heterostructure microwave semiconducting devices make strong candidates for integration since they have shown significantly lower noise figures at liquid nitrogen temperatures. 3,4

In deep. space communications, radio astronomy and radiometer applications, low noise and low loss requirements are frequently met by cooling the microwave components. For the first time we have combined in a hybrid circuit a superconducting microstrip bandpass filter and a GaAs low noise amplifier (LNA), which is a basic building block in these applications. We compared its performance to a hybrid gold filter/LNA circuit operating at the same temperature. The circuit design, fabrication, and experimental results are presented below.

\section{Circuit Design and Fabrication}

A two-pole microstrip bandpass filter was designed with a 2.5 percent bandwidth, $0.5 \mathrm{~dB}$ passband ripple, and $7.5 \mathrm{GHz}$ center frequency on lanthanum aluminate substrate. The layout of the two-pole filter is shown in Fig. 1. The filter was fabricated using laser ablated YBCO superconducting films $(-5000 \mathrm{~A})$ on a $10 \mathrm{mil}$ lanthanum aluminate substrate. A gold film deposited by E-beam evaporation on the opposite side of lanthanum aluminate substrate was used as a ground plane. An identical filter using gold film for the microstrip and the ground was also fabricated.

The LNA selected was an Avantek Inc. PGM 11421 with a specified frequency response from 4 to $11 \mathrm{GHz}$, a minimum gain of $8.0 \mathrm{~dB}$, and a typical noise figure of $2.5 \mathrm{~dB}$. The bandpass filter/GaAs LNA hybrid was mounted in a brass test fixture as shown in Fig. 2. The devices were connected by 10 mil gold bond wires to $50 \Omega$ input/output microstrip lines that were fabricated on 10 mil thick Duroid $\left(\varepsilon_{r}=2.3\right)$ substrate. The length of the microstrip lines were chosen so as to minimize the interaction between the launcher pins and the devices.

The coax to microstrip transition was implemented using SMA female flange connectors. Silver paint was used to improve the contact between the center conductor of the launcher and the microstrip line.

\section{Cryogenic Measurements and Results}

The LNA and bandpass filters were tested individually to verify their performance at $T=300$ and $77 \mathrm{~K}$. An $\mathrm{HP} 8510 \mathrm{~B}$ automatic network analyzer (ANA) was used to measure insertion gain or loss, and a HP 8970A noise figure meter was used to determine the noise figure of the LNA. Table 1 presents a summary of the pertinent results that apply for this work. The data for the gold filter shows a reduction in the insertion loss of $1.4 \mathrm{~dB}$ between $\mathrm{T}=300$ and $77 \mathrm{~K}$. This is due to lower ohmic loss in the gold conductor and to a reduction of loss in the dielectric substrate at $\mathrm{T}=77$ versus $300 \mathrm{~K}$. The HTS filter shows a significantly smaller insertion loss than the gold filter at $77 \mathrm{~K}$. This is due to the near elimination of conductor loss in the YBCO film compared to the loss in the gold conductor. Most of the loss present of the HTS filter is due to the use of a gold ground plane.

The primary advantage in using an HTS filter over a gold filter is that the HTS filter offers a much smaller insertion loss. If the HTS filter's gold ground plane were replaced with HTS material, a further reduction in insertion loss could be achieved.

For the LNA/bandpass filter hybrid measurements, a full two port calibration was performed inside the cryostat so as to move the ANA reference planes to the ends of the semi-rigid cables 
inside the cryostat. Since this experiment is concerned only with the relative difference in gain of the hybrid circuit and not with the absolute gain, a two port calibration was selected over a TRL or LRL calibration, which could move the reference planes of the ANA onto the test fixture, thereby removing its effect as well. In all measurements performed, only the filters were changed in the test fixture.

To calibrate the noise figure meter, the LNA/bandpass filter was replaced in the test fixture by a $50 \Omega$ thru line supplied by Avantek Inc. An ANA measurement was made to determine the total insertion loss of the test fixture and semi-rigid cables over the frequency range of 7.0 to $8.0 \mathrm{GHz}$. This loss was found to be $2.6 \mathrm{~dB}$ in this frequency range. One half of this loss (1.3 dB), representing the loss of that portion of the test fixture that appears at the input of the hybrid, was subtracted away from the noise figure measurements that were made on the hybrid at the appropriate frequency points, leaving only the actual noise figure of the hybrid.

Figure 3 shows the difference in the hybrid's gain when gold and HTS filters, respectively, are used, while Fig. 4 shows the difference in the noise figures. Since the HTS filter becomes functional only after the system reaches cryogenic temperatures, there is no room temperature data provided for it. This particular filter was fabricated on a high quality substrate, it began to conduct at $\mathrm{T}=89 \mathrm{~K}$, and reached its minimum insertion loss at $\mathrm{T}=85 \mathrm{~K}$.

At $77 \mathrm{~K}$ the gold filter/LNA hybrid shows a noise figure improvement of nearly $3.5 \mathrm{~dB}$ as compared to $300 \mathrm{~K}$, while the HTS filter/LNA hybrid shows a $5.5 \mathrm{~dB}$ improvement in noise figure compared to gold at $300 \mathrm{~K}$. As expected, the overall gain of the HTS filter/LNA hybrid is greater than that of the gold hybrid due to a lower insertion loss of the HTS filter.

As a check on the accuracy of these results, the data obtained for the LNA and filters individually is inserted in the expression for the noise figure of a cascade, $F_{1}=F_{1}+\left(F_{2}-1\right) / G_{1}$. Here, $F_{1}$ and $F_{2}$ are the noise figures of the filter and LNA respectively, and $G_{1}$ is the loss of the filter. Table 2 shows the results for the minimum noise figure of the hybrid. There is good agreement between the calculated and measured noise figures for the hybrid.

\section{Conclusions}

A low loss two-pole $\mathrm{Y}-\mathrm{Ba}-\mathrm{Cu}-\mathrm{O}$ superconducting bandpass filter on lanthanum aluminate substrate was connected in series with a packaged GaAs low noise amplifier and fully characterized at $77 \mathrm{~K}$. The noise figure characteristics of the superconducting filter/LNA hybrid circuit when compared to the gold filter/LNA hybrid circuit showed an improvement of $2.1 \mathrm{~dB}$ at $77 \mathrm{~K}$. The gain characteristics showed an improvement of $0.5 \mathrm{~dB}$ for the HTS filter hybrid over the gold hybrid at $77 \mathrm{~K}$.

This first demonstration of superconducting filter/GaAs LNA hybrid circuit shows potential for applications in radio astronomy, radiometers and deep space communications systems where high performance is desired in spite of the cooling requirements.

\section{Acknowledgment}

The authors wish to acknowledge the assistance of Mr. Ed Rylander, Sr. Test Engineer at Avantek Inc., Folsom, CA for his useful discussions on noise figure measurement and for supplying us with Avantek thru lines for calibration purposes.

\section{References}

1. IEEE Trans. Microwave Theory Tech., vol. 39, no. 9, 1991 (entire issue).

2. D.C. Webb and M. Nisenoff, "The high temperature superconductivity space experiment," Microwave J., vol. 34, pp. 85-91, 1991.

3. M.W. Pospieszalski, S. Weinreb, R.D. Norrod, and R. Harris, -FET's and HEMT's at cryogenic temperatures-their properties and use in low-noise amplifiers," IEEE Trans. Microwave Theory Tech., vol. 36, pp. 552-560, 1988.

4. S. Weinreb, "Low-noise, cooled GASFET amplifiers," IEEE Trans. Microwave Theory Tech., vol. 28, pp. 1041-1054, 1980.

TABLE 1.-DATA ON THE LNA AND BANDPASS FILTERS USED IN THIS EXPERIMENT

[The frequency range is 7.0 to $8.0 \mathrm{GHz}$. The gain/loss values shown are average values over this frequency band. For the filters, noise figure values were taken to be the magnitude of the respective insertion loss.]

\begin{tabular}{|ll|c|c|}
\hline & & $\begin{array}{c}\text { Gain/loss, } \\
\mathrm{dB}\end{array}$ & $\begin{array}{c}\text { Noise figure, } \\
\mathrm{dB}\end{array}$ \\
\hline LNA (PGM 11421) & $\mathrm{T}=300 \mathrm{~K}$ & 8.9 & 2.5 \\
& $\mathrm{~T}=77 \mathrm{~K}$ & 9.5 & 0.9 \\
\hline \multirow{2}{*}{ Gold filter } & $\mathrm{T}=300 \mathrm{~K}$ & -4.2 & 4.2 \\
& $\mathrm{~T}=77 \mathrm{~K}$ & -2.8 & 2.8 \\
\hline HTS filter & $\mathrm{T}=77 \mathrm{~K}$ & -0.5 & 0.5 \\
\hline
\end{tabular}


TABLE 2.-CALCULATED AND MEASURED VALUES FOR THE NOISE FIGURE

\begin{tabular}{|l|c|c|}
\hline & $\begin{array}{c}\text { CF THE HYBRID CIRCUIT } \\
\text { noise figure } \\
\mathrm{dB}\end{array}$ & $\begin{array}{c}\text { Measured } \\
\text { noise figure, } \\
\mathrm{dB}\end{array}$ \\
\hline Gold filter/LNA, $\mathrm{T}=300 \mathrm{~K}$ & 6.7 & 7.0 \\
\hline Gold filter/LNA, $\mathrm{T}=77 \mathrm{~K}$ & 3.7 & 3.6 \\
\hline HTS filter/LNA, $\mathrm{T}=77 \mathrm{~K}$ & 1.4 & 1.5 \\
\hline
\end{tabular}

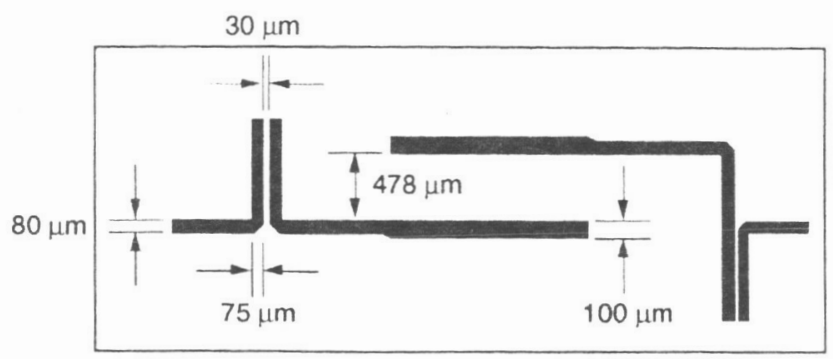

Figure 1.-Layout of the C-band, two pole bandbass filter.

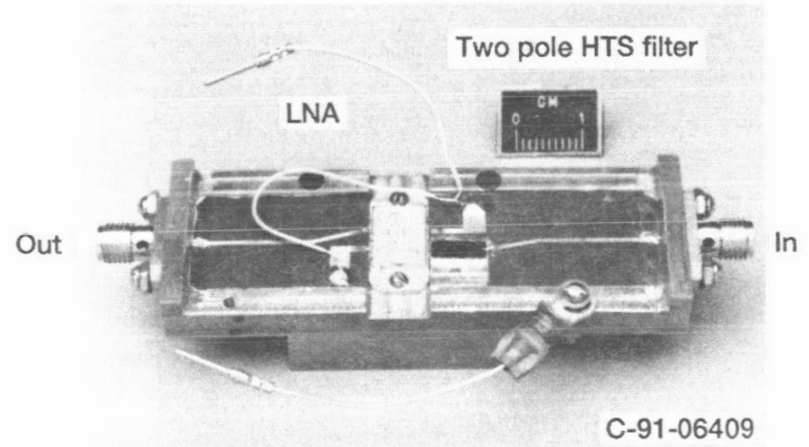

Figure 2.-Test fixture used for measurements on bandpass filter/LNA hybrid.

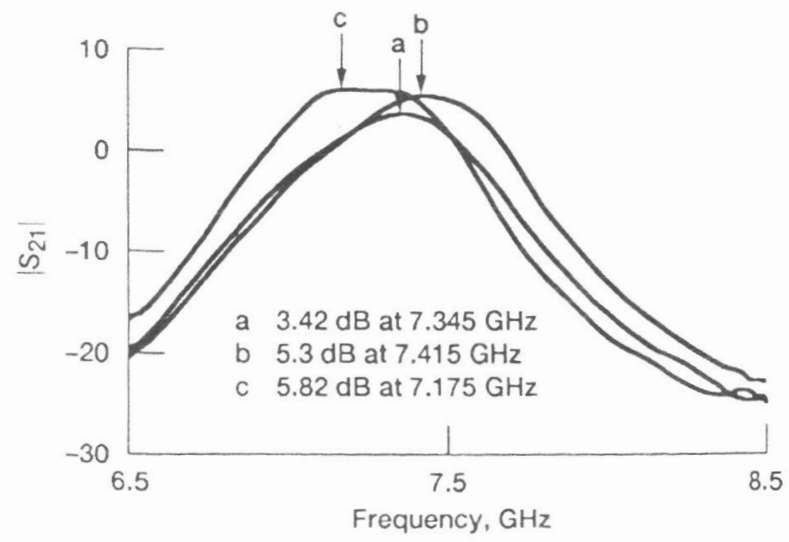

Figure 3.-Forward transmission (gain) of the gold filter/LNA hybrid (a) at $T=300 \mathrm{~K}$, (b) at $\mathrm{T}=77 \mathrm{~K}$, and (c) the HTS filter/ LNA hybrid at $T=77 \mathrm{~K}$.

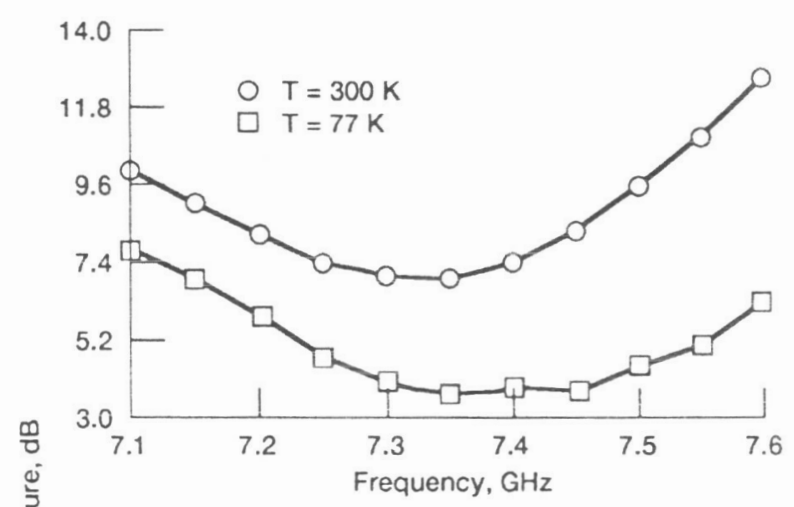

(a) Gold filter/LNA hybrid.

$\frac{0}{2}$

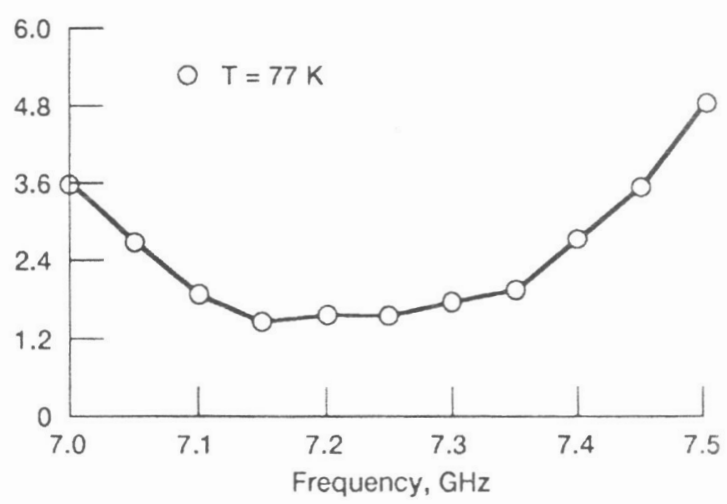

(b) HTS filter/LNA hybrid.

Figure 4.-Noise figure measurement as a function of temperature.

ORIGINAL PAGE

BLACK AND WHITE PHOTOGRAPH 


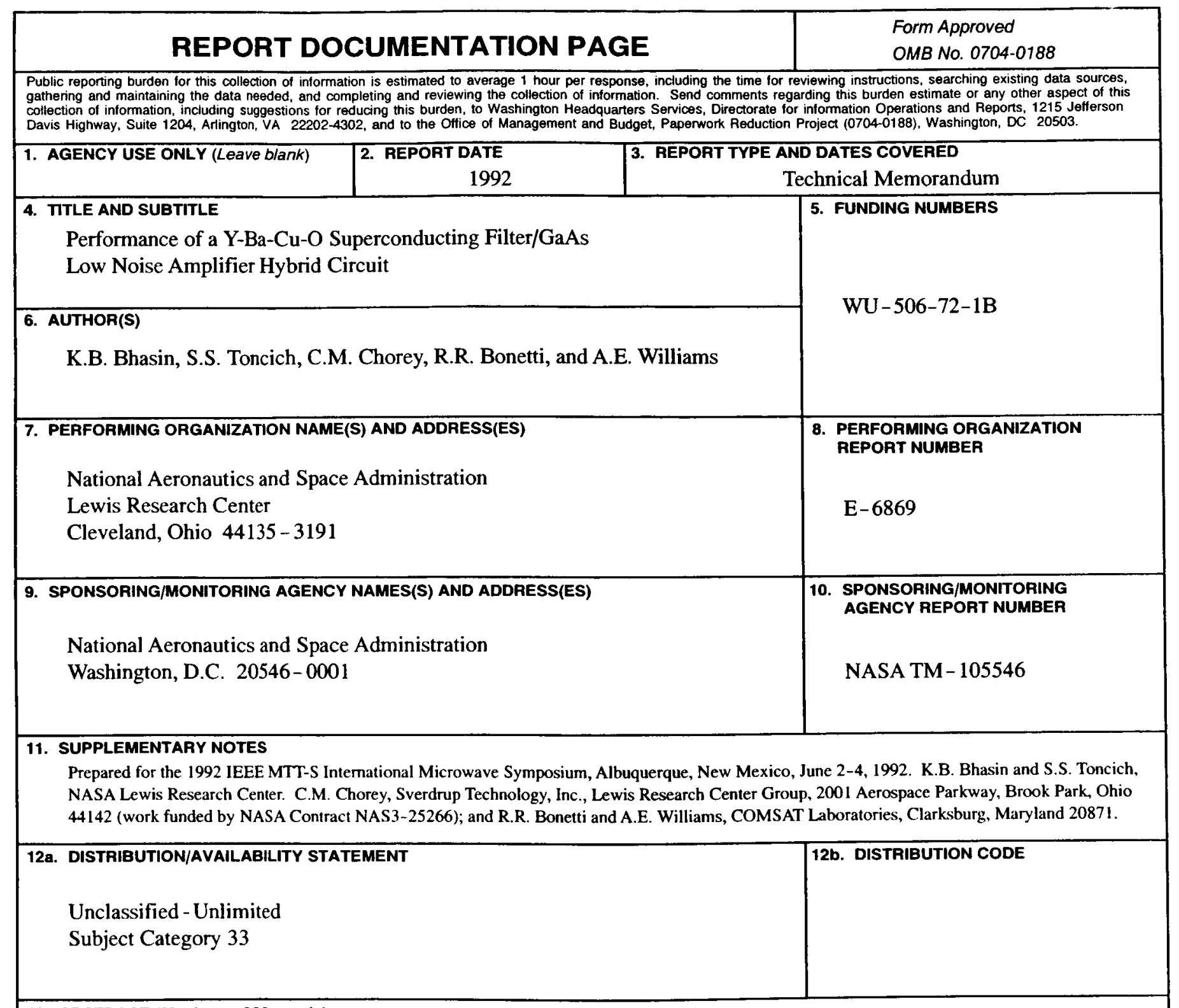

\section{ABSTRACT (Maximum 200 words)}

A superconducting $7.3 \mathrm{GHz}$ two-pole microstrip bandpass filter and a GaAs low noise amplifier (LNA) were combined into a hybrid circuit and characterized at liquid nitrogen temperatures. This superconducting/semiconducting circuit's performance was compared to a gold filter/GaAs LNA hybrid circuit. The superconducting filter/GaAs LNA hybrid circuit showed higher gain and lower noise figure than its gold counterpart.

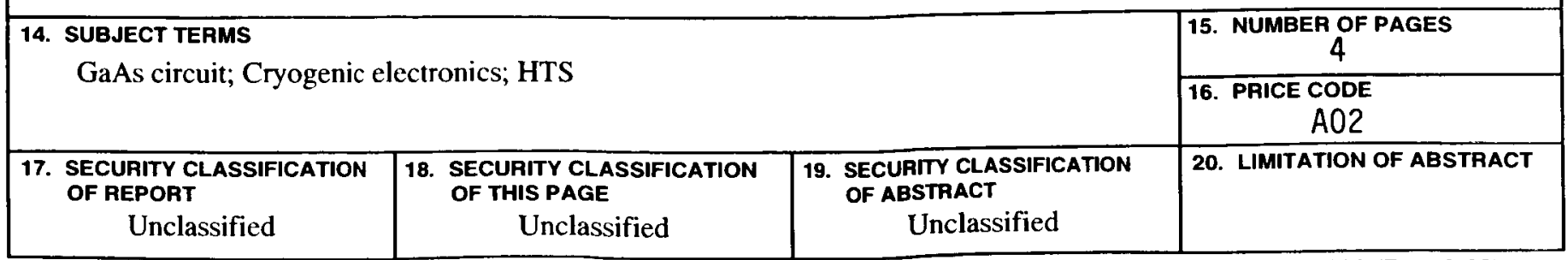

